\title{
Long-term low-dose antibiotics in recalcitrant chronic rhinosinusitis: a retrospective analysis*
}

\author{
W.J.M. Videler, K. van Hee, S.M. Reinartz, C. Georgalas, \\ F.W. van der Meulen, W.J. Fokkens \\ Department of Otorhinolaryngology, Academic Medical Centre, Amsterdam, The Netherlands
}

Rhinology 50: 45-55, 2012 DOI: 10.4193/Rhino11.123 *Received for publication: June 6, 2011

accepted: November 22, 2011

\section{Summary}

Introduction: In recalcitrant Chronic RhinoSinusitis (CRS) treatment with intranasal corticosteroids, short-term antibiotics and even sinus surgery is frequently insufficient. Long-term low-dose administration of antibiotics has been suggested as a treatment option in these patients. We analysed the outpatient clinic population treated with different long-term low-dose antibiotics at the AMC Amsterdam.

Patients and methods: Eligible patients, who were treated with trimethoprim-sulfamethoxazole or macrolides, were retrospectively identified from our outpatient clinic in 2009. The two main outcome measures were sinonasal complaints and nasal endoscopic findings. A 5-point grading scale was used to score the results compared with the pre-treatment situation. This was measured at several time-points during, and after the antibiotic course, and at the end of the follow-up term.

Results: Seventy-six patients were included, 53 per cent had asthma and all of them had undergone sinus surgery. Seventyeight per cent showed improvement of the symptoms, and 84 per cent demonstrated improvement of the sinonasal mucosa at the end of the course. No significant difference was found between the trimethoprim-sulfamethoxazole and macrolide group.

Discussion: Long-term low-dose treatment with antibiotics seems to improve CRS symptoms and the appearance of the sinonasal mucosa on nasal endoscopy. However, at this stage, strong conclusions are immature because no placebo-group has been included. Despite increasing use of long-term low-dose treatment of recalcitrant CRS in referral centres, hard clinical evidence is lacking. More research is urgently required.

Key words: chronic rhinosinusitis, antibiotic treatment, long-term low-dose, oral administration, retrospective

\section{Introduction}

In the last decades, the management of Chronic RhinoSinusitis (CRS) has improved substantially. According to the EP3OS-management-schemes, patients with CRS are primarily treated with nasal saline irrigation, intranasal corticosteroids, and in more severe cases with antibiotics and/or systemic steroids. In patients who do not optimally respond to this strategy, Endoscopic Sinus Surgery (ESS) is performed ${ }^{(1-6)}$. Because CRS could be considered a chronic mucosal disease, in some cases with participation of the underlying bone or biofilm, long-term low-dose antibiotics are administered more frequently in tertiary referral centres. Ho- wever, evidence for this treatment regime in literature is limited and weak.

The department of Otorhinolaryngology at the Academic Medical Centre AMC Amsterdam is a tertiary care centre for patients with CRS. All the patients referred have already been treated with medical therapy, and a vast majority of them already have undergone ESS. After careful evaluation with rigid nasal endoscopy, CT scan of the paranasal sinuses, laboratory investigation, allergy testing, smell testing and nasal culturing, an optimal management regime is started including intensive 
nasal saline irrigation (with or without baby shampoo) $)^{(7)}$, intranasal corticosteroids, antibiotics, systemic corticosteroids and if needed several more tailored medical treatments with less scientific proof like local antibiotics, leucotrienes antagonists, anti-lgE, and trial drugs or new ways of medication delivery (8-10). If this treatment is insufficient, patients with recalcitrant CRS are given the choice to either have long-term low-dose antibiotic treatment or revision surgery. This revision sinus surgery again is embedded in maximal medical therapy. When patients choose to start with long-term antibiotic treatment, in most of the cases we start with an arbitrarily chosen 3 months treatment period, which is prolonged when proven effective. A substantial group appears to respond to this regime in both symptom reduction and improvement of the sinus mucosa evaluated with rigid nasal endoscopy. The long-term low-dose treatment is ended when patients are in a stable situation for some time, this can be after many months of treatment. Liver and renal functions are monitored every 6 weeks. If this regime still is insufficient, as a final resort medial maxillectomy ((endonasal) Denker's procedure) (11-13) and/or extensive frontal surgery (Draf III) is performed (14-16). A life-long nasal rinsing regime is an inevitable consequence of this type of radical surgery.

Although the pathophysiology of CRS is poorly understood, it is considered a mucosal disease with many different phenotypes. External factors like bacteria, fungi and viruses can initiate the chronic infection. However, the host response can vary, and the same stimuli can give different results in different patients. This reaction in severe cases eventually leads to mucosal swelling, increased number of seromucous glands, remodelling of the ciliated epithelium, combined with an infiltration with inflammatory cells, possibly leading to a vicious cycle. The infectious aetiology in combination with the constant inflammation could justify the use of long-term, low-dose antibiotics with antimicrobial as well as immunomodulatory properties.

At our centre, most prescribed antibiotics for this purpose are trimethoprim-sulfamethoxazole and macrolide antibiotics, mostly azithromycin and clarythromycin. Trimethoprim and sulfamethoxazole inhibit different enzymatic steps of the folic acid pathway, leading to cessation of bacterial synthesis of thymidine monophosphate (dTMP) via thymidylate synthase ${ }^{(17-18)}$. We found no literature on the prolonged treatment with trimethoprim-sulfamethoxazole in CRS. In research most attention, especially in vitro, was put to the antibiotics of the macrolide family. Besides their antimicrobial effects, the mechanism of macrolides is thought to be anti-inflammatory, based on the blockage of the production of pro-inflammatory cytokines, such as interleukin-8 (IL-8) and tumour necrosis factor- $a$ (TNF- $a$ ), combined with effects on neutrophil migration and adhesion, and modulation of synthesis and secretions of mucus ${ }^{(19-20)}$. Both trimethoprimsulfamethoxazole and macrolides have proven to be prescribed safely for a prolonged time. Trimethoprim-sulfamethoxazole is widely used for long-term prophylaxis and treatment of infections of the urinary and respiratory tracts ${ }^{(21-23)}$. Low-dose long-term macrolides also proved to be safe and have been investigated in a small number of studies. The majority of the uncontrolled investigations evaluated macrolides using varying outcome measures, and have suggested clinical benefit ${ }^{(24-27)}$. In a prospective, randomized controlled trial comparing medical and surgical therapy for patients with CRS, the authors have demonstrated that prolonged treatment with antibiotics and FESS were equally effective up to one year ${ }^{(28)}$. In the first performed, double-blind, randomized, placebo-controlled trial on the efficacy of 3 months macrolide treatment in 64 CRS-patients, no significant differences were found. However, a significant benefit of macrolides over placebo was shown in a subpopulation of patients with low IgE. In this group, Sino-Nasal Outcome Test-20 (SNOT-20), nasal endoscopy, saccharine transit time, and IL-8 levels in nasal lavage fluid improved in the antibiotic arm compared with placebo ${ }^{(29)}$. In a recent RCT on the efficacy of methylprednisolone and a member of another antibiotic family (doxycycline) in 47 patients, a significant effect on nasal polyp size, nasal symptoms, and mucosal and systemic inflammation markers was demonstrated in both treatment arms ${ }^{(30)}$.

In an attempt to further evaluate the efficacy of long-term lowdose antibiotics as an alternative treatment option for recalcitrant CRS, we retrospectively analysed the outpatient clinic population treated with prolonged antibiotics at our tertiary care centre.

\section{Patients and methods}

Patients

All patients met the $\mathrm{EP}^{3} \mathrm{OS}$ criteria for $\mathrm{CRS}{ }^{(31)}$, and all had a history of extensive medical treatment and sinus surgery. Patients did not use an antibiotic course within 1 month, nor did they undergo sinus surgery within 3 months before start of the evaluated long-term low-dose antibiotic course. Exclusion criteria for this retrospective evaluation were: massive nasal polyposis (grade 2 and 3), impairment of liver or renal function, cystic fibrosis, immune deficiency needing intravenous immunoglobulins, and systemic diseases affecting the nose and paranasal sinuses (e.g., Wegener's granulomatosis or sarcoidosis). Most patients used nasal saline irrigation daily. Intranasal or pulmonary steroids were allowed, under the restriction that the dosage did not increase twice or more, during the evaluated antibiotic course.

Long-term low-dose antibiotic therapy Two different families of orally administered long-term lowdose antibiotics were evaluated in this study. Trimethoprimsulfamethoxazole was prescribed in a dosage of $960 \mathrm{mg}$ twice daily during 2 weeks, followed by $960 \mathrm{mg} /$ day in the next weeks of treatment. A second cohort of patients was treated with ma- 
crolides of which azithromycin was administered in most cases, in a dosage of $500 \mathrm{mg}$ daily, which was in some cases reduced to every other day, twice a week or even once a week depending on the clinical picture. Azithromycin has pharmacokinetic properties, which allow, even after a single dose once weekly, persistently elevated concentrations in tissue ${ }^{(32-35)}$. In 5 cases, clarythromycin, another member of the macrolide family, was prescribed in a dosage of $250 \mathrm{mg}$ twice daily in the first 2 weeks, prolonged with $250 \mathrm{mg} /$ day.

\section{Study design}

Eligible patients were retrospectively identified from the outpatient clinic of the department of otorhinolaryngology in 2009. Corresponding records were collected and studied by at least 2 of the authors independently. Collaborating members of our team of rhinologists performed all recorded examinations during outpatient visits. The two main outcome measures were: sinonasal complaints and nasal endoscopic findings. A 5-point grading scale was used to score the results compared to the pre-treatment situation: worse (-1); no change (0); moderate improvement (1); good improvement (2); cured (3). The main time-points assessed were: after 6 and 12 weeks and after 6,12 , and 24 months. Extra time points included: at the end of the course, and at the end of the follow-up term. We also have divided the group in responders and non-responders. Responders were the patients who showed moderate to good improvement, or reported they were cured (score 1 to 3 ). Non-responders showed no improvement or got worse (score -1 and 0). Evaluation was terminated in most cases when no more data were available, mainly because of lost to follow-up, while patients with satisfying results were sent back to their referral doctors. Other end-points were: substantial medical intervention, or new sinus surgical procedure.

\section{Statistical analysis}

All data were entered into a computerized database and analysis was conducted using statistical software package SPSS version 16.0 statistical software, after consulting a medical statistician. Wilcoxon singed ranks tests were performed to evaluate the effect of antibiotic treatment on different time-points. Mann Whitney $\mathrm{U}$ tests, Kaplan Meier curves and Log Rank tests were used to assess statistical differences between the 2 different antibiotic groups. The Fischer exact test was used to compare patient characteristics between responders (moderate improvement, good improvement or cured) and non-responders (worse or no change).

\section{Results}

\section{Patient characteristics}

Of the 104 patients identified at the outpatient clinic, 28 patients met 1 of the exclusion criteria or documentation was insufficient. Seventy-six patients were included and evaluated. In all patients conventional medical treatment as described above did not substantially relief symptoms. All of them underwent sinus surgery, with a median of 2.9 procedures. Aspirin sensitivity was diagnosed by history. Aspirin provocation is not part of the routine at our hospital. Seventy-four out of 76 patients used nasal corticosteroids during the evaluated course. All patients got the advice to rinse the nose with saline solution daily. Due to the retrospective set up of this analysis, the length of the course of antibiotics was variable, with a minimum of 79 days. The mean follow-up time after stop of the antibiotic administration for the total group was 4.7 months (trimethoprim-sulfamethoxazole: 4.9 months, macrolides: 4.4 months). Complete patient characteristics are displayed in Table 1.

\section{Duration of course}

The mean length of the trimethoprim-sulfamethoxazole course was 232 days (range, 81 - 802). For the macrolides this was 189 days (range, 79 - 601). Responders who's sinonasal symptoms improved did have a mean antibiotic course of 232 days. In the group of non-responders, the mean length of the course was 150 days. Patients whose endoscopic findings responded well used a long-term low-dose course of 223 days. In the nonresponding group this was 166 days.

\section{Efficacy of long-term low-dose antibiotics}

Symptoms and nasal endoscopic findings were scored after 6 and 12 weeks and after 6,12 , and 24 months. Because there were too many missing data on 6 weeks, and 12 and 24 months, results could not be reported. We decided to focus on two other main time-points: the cessation of the antibiotic course and the end of follow-up.

In the total group, sinonasal symptoms responded well (moderate improvement to cure, score 1 to 3 ) in 59 patients (78\%). After a mean follow-up of 4.7 months after cessation of the antibiotic course, still 52 patients (68\%) were present in this wellresponding group. The nasal endoscopic findings showed similar results. During the antibiotic course, nasal endoscopy in the total group showed response (moderate improvement to cure) in 64 patients (84\%). After cessation of the antibiotic course and the mean follow-up of 4.7 months, 58 (76\%) patients were recorded to have an improvement of the nasal mucosa on endoscopy. Although the results at the end of follow-up for both symptoms and endoscopy were still satisfactory, the decrease in score over time was statistically significant (symptoms $p=$ 0.003 , endoscopy $p=0.001$ ). All the percentages and results are shown in Table 2.

At the end of the antibiotic course 5 patients responded well on endoscopy, but were scored as non-responder at the symptom score. At the end of follow-up, 6 patients were responder on endoscopy but were non-responders on the symptom score. 
Videler et al.

Table 1. Patient characteristics.

Patients

Male:female

Median age

Sinonasal complaints (median)

Number of previous procedures (median)

Allergy

Asthma

Mild nasal polyposis

ASA

Active smoker

Previous surgery:

Infundibulotomy

Ethmoidectomy

Sphenoidectomy

Frontal surgery

Polypectomy

Claoué

Caldwell-Luc

Denker

Draf III

\begin{tabular}{|c|c|c|}
\hline Total & TSM & MAC \\
\hline 76 & 43 & 33 \\
\hline $38: 38$ & $20: 23$ & $18: 15$ \\
\hline 47 year (range, $12-70$ ) & 46 & 48 \\
\hline 10.9 year (range, $1-40$ ) & 10.3 & 11.7 \\
\hline 2.9 (range, 1-14) & 2.9 & 2.9 \\
\hline $40 \%$ & $30 \%$ & $52 \%$ \\
\hline $53 \%$ & $49 \%$ & $58 \%$ \\
\hline $65 \%$ & $67 \%$ & $61 \%$ \\
\hline $11 \%$ & $9 \%$ & $12 \%$ \\
\hline $9 \%$ & $9 \%$ & $9 \%$ \\
\hline $100 \%$ & $100 \%$ & $100 \%$ \\
\hline $100 \%$ & $100 \%$ & $100 \%$ \\
\hline $100 \%$ & $100 \%$ & $100 \%$ \\
\hline $4 \%$ & $5 \%$ & $3 \%$ \\
\hline $8 \%$ & $12 \%$ & $3 \%$ \\
\hline $36 \%$ & $37 \%$ & $33 \%$ \\
\hline $12 \%$ & $9 \%$ & $15 \%$ \\
\hline $5 \%$ & $7 \%$ & $3 \%$ \\
\hline $5 \%$ & $7 \%$ & $3 \%$ \\
\hline $13 \%$ & $12 \%$ & $15 \%$ \\
\hline
\end{tabular}

TSM: trimethoprim-sulfamethoxazole; MAC: macrolides

Table 2. Results during the use of antibiotics versus results at the end of follow-up.

\begin{tabular}{|c|c|c|c|}
\hline symptoms & $\begin{array}{l}\text { during antibiotic } \\
\qquad n=76\end{array}$ & $\begin{array}{l}\text { end of follow-up } \\
n=76\end{array}$ & test for change in time* \\
\hline-1 worse & $1.3 \%$ & $1.3 \%$ & \multirow{7}{*}{$p=0.003$} \\
\hline 0 no change & $21.1 \%$ & $30.3 \%$ & \\
\hline 1 moderate improvement & $36.8 \%$ & $39.5 \%$ & \\
\hline 2 good improvement & $31.6 \%$ & $22.4 \%$ & \\
\hline 3 cured & $9.2 \%$ & $6.6 \%$ & \\
\hline mean score & 1.3 & 1.0 & \\
\hline median score (IQR) & $1(1-2)$ & $1(0-2)$ & \\
\hline endoscopic findings & $\begin{array}{l}\text { during antibiotic } \\
\qquad=76\end{array}$ & $\begin{array}{l}\text { end of follow-up } \\
\qquad n=76\end{array}$ & test for change in time* \\
\hline-1 worse & $1.3 \%$ & $1.3 \%$ & \multirow{7}{*}{$p=0.001$} \\
\hline 0 no change & $14.5 \%$ & $22.4 \%$ & \\
\hline 1 moderate improvement & $38.2 \%$ & $43.4 \%$ & \\
\hline 2 good improvement & $31.6 \%$ & $22.4 \%$ & \\
\hline 3 cured & $14.5 \%$ & $10.5 \%$ & \\
\hline mean score & 1.5 & 1.2 & \\
\hline median score (IQR) & $1(1-2)$ & $1(1-2)$ & \\
\hline
\end{tabular}

*Wilcoxon signed ranks test 
No patients scored better on the symptom score than on nasal endoscopy.

Trimethoprim-sulfametoxazole vs. macrolides

Sinonasal symptoms responded well (moderate improvement to cure) in 34 patients (79\%) treated with long-term low-dose trimethoprim-sulfamethoxazole. At the end of a follow-up of 4.9 months, this was decreased to $70 \%$ of the patients. Five patients (12\%) were symptom free at the end of the course and $4(9 \%)$ at the end of follow-up. Sinonasal symptoms of patients treated with macrolides responded well in 25 patients $(76 \%)$ at the end of treatment. At the end of a mean follow-up of 4.4 months, this was decreased to $67 \%$. During the course, 2 patients (6\%) reported they were symptom-free. After the stop of the course, mild symptoms recurred in one of them.

The nasal endoscopic findings improved (moderate improvement to cure) in 36 patients (84\%) at the end of the trimethoprim-sulfamethoxazole treatment period, which decreased to $72 \%$ at the end of follow-up. Nasal endoscopic findings were graded as cured in 6 patients (14\%) during the course, which decreased to $5(12 \%)$ after stop of the treatment. In the macrolide cohort, nasal endoscopic findings responded well in 28 patients (85\%). At the end of follow-up a limited back-fall was found to $82 \%$. Nasal endoscopic findings were graded as cured in 5 patients $(15 \%)$ during the course, which decreased to 3 patients (9\%) at the end of follow-up.

We compared the scores of trimethoprim-sulfamethoxazole with the macrolides results. In this studied population, no significant differences were found between trimethoprimsulfamethoxazole and macrolides neither in de symptoms, nor in nasal endoscopic findings (Table 3). We reassessed the data comparing the trimethoprim-sulfamethoxazole patients to the azithromycin group by leaving the clarithromycin patients out. No substantial differences were found in the datasets with or without clarythromycin. An additional analysis was performed with Kaplan Meier curves. The total percentage of responders in time for both trimethoprim-sulfamethoxazole and macrolides were displayed and analysed with a Log Rank test. Again no significant difference was found between the 2 antibiotic groups (See for the symptom and endoscopy Kaplan Meier curves Figure 1 and Figure 2, respectively).

Five patients in the macrolide group and 7 patients in the trimethoprim-sulfamethoxazole group used a short course of systemic corticosteroids at the start of the antibiotics. Closer inspection did not reveal a substantial better score than patients without an additional corticosteroid course at the start, although numbers are too small to draw definite conclusions. In a small group of patients, 3 in both groups, there was lack of signs of improvement. Therefore, they were scheduled for sinus surgery and follow-up was terminated.

\section{Subgroup analysis}

In an attempt to find patient characteristics with prognostic value, we evaluated the occurence of mild nasal polyps, allergy, bloodeosinophils, asthma, ASA-triad, and smoking. In the symptom, as well as the nasal endoscopy data, none of the patient characteristics were significantly different when comparing the responding and non-responding group, but the numbers were small. The blood eosinophils were available in 66 of the patients. In the responder group 33\% and in the nonrespondergroup 43 percent had hypereosinophilia. The difference was not significant using the Fischer exact test. Other percentages and results of the Fischer exact test are shown in Table 4.

\section{Side effects}

No serious adverse events were observed. Three complaints possibly related to long-term low-dose antibiotics were reported. One patient treated with the macrolide azithromycin mentioned mild muscle-aches during the prolonged course, without a reason to end the administration. In the 5 patients with long-term low-dose clarythromycin of the macrolide group, there were 2 patients complaining of mild, reversible skin rash. In all 3 events there was no reason to end the course. No adverse events were reported in the trimethoprim-sulfamethoxazole group.

\section{Discussion}

In the majority of patients suffering from recalcitrant CRS, no underlying aetiology is found. Suspects under attention are: superantigens ${ }^{(36-40)}$, fungal infections ${ }^{(41-45)}$, inflammation of the underlying bone ${ }^{(46-49)}$, biofilm ${ }^{(50)}$, and intracellular presence of bacteria in the epithelial cells of the middle meatus mucosa (51-52). Long-term low-dose antibiotics are believed to be useful in the treatment of recalcitrant CRS, not only in the battle against microorganisms, but also because of the pretended immunomodulatory qualities. The mechanism behind this is not well understood, but probably involves down-regulation of the local host immune response as well as a downgrading of the virulence of the colonizing bacteria. However, there is lack of evidence in terms of placebo-controlled, double-blind, randomized trials.

The antibiotics evaluated in the present study are trimethoprim-sulfamethoxazole and macrolides. As mentioned in the introduction, there are reports on macrolides in the treatment of CRS, but the use of Trimethoprim-sulfamthoxazole seems to be a novelty in this perspective. Both antibiotics have more or less the same antibiotic spectrum. This includes the coverage of the sinonasal colonizer Staphylococcus aureus, but Pseudomonas aeruginosa for example is not covered. Although trimethoprim-sulfamethoxazole is prescribed long-term low-dose in 


\begin{tabular}{|c|c|c|c|}
\hline symptoms during antibiotics & $\begin{array}{l}\text { trimethoprim-sulfamethoxa- } \\
\text { zole } n=43\end{array}$ & $\begin{array}{l}\text { macrolides } \\
\qquad n=33\end{array}$ & $\begin{array}{l}\text { test for difference between } \\
\text { antibiotics type* }\end{array}$ \\
\hline-1 worse & $0 \%$ & $3 \%$ & \multirow{7}{*}{$p=0.609$} \\
\hline 0 no change & $20.9 \%$ & $21.2 \%$ & \\
\hline 1 moderate improvement & $37.2 \%$ & $36.4 \%$ & \\
\hline 2 good improvement & $30.2 \%$ & $33.3 \%$ & \\
\hline 3 cured & $11.6 \%$ & $6.1 \%$ & \\
\hline mean score & 1.3 & 1.2 & \\
\hline median score (IQR) & $1(1-2)$ & $1(0.5-2)$ & \\
\hline symptoms at end of follow-up & $\begin{array}{l}\text { trimethoprim-sulfamethoxa- } \\
\text { zole } n=43\end{array}$ & $\begin{array}{l}\text { macrolides } \\
n=33\end{array}$ & $\begin{array}{l}\text { test for difference between } \\
\text { antibiotics type* }\end{array}$ \\
\hline-1 worse & $0 \%$ & $3 \%$ & \multirow{7}{*}{$p=0.804$} \\
\hline 0 no change & $30.2 \%$ & $30.3 \%$ & \\
\hline 1 moderate improvement & $46.5 \%$ & $30.3 \%$ & \\
\hline 2 good improvement & $14 \%$ & $33.3 \%$ & \\
\hline 3 cured & $9.3 \%$ & $3 \%$ & \\
\hline mean score & 1 & 1 & \\
\hline median score (IQR) & $1(0-1)$ & $1(0-2)$ & \\
\hline endoscopy during antibiotics & $\begin{array}{l}\text { trimethoprim-sulfamethoxa- } \\
\text { zole } n=43\end{array}$ & $\begin{array}{l}\text { macrolides } \\
n=33\end{array}$ & $\begin{array}{l}\text { test for difference between } \\
\text { antibiotics type* }\end{array}$ \\
\hline-1 worse & $0 \%$ & $3 \%$ & \multirow{7}{*}{$p=0.996$} \\
\hline 0 no change & $16.3 \%$ & $12.1 \%$ & \\
\hline 1 moderate improvement & $37.2 \%$ & $39.4 \%$ & \\
\hline 2 good improvement & $32.6 \%$ & $30.3 \%$ & \\
\hline 3 cured & $14 \%$ & $15.2 \%$ & \\
\hline mean score & 1.4 & 1.4 & \\
\hline median score (IQR) & $1(1-2)$ & $1(1-2)$ & \\
\hline endoscopy at the end of follow-up & $\begin{array}{l}\text { trimethoprim-sulfamethoxa- } \\
\text { zole } n=43\end{array}$ & $\begin{array}{c}\text { macrolides } \\
n=33\end{array}$ & $\begin{array}{l}\text { test for difference between } \\
\text { antibiotics type* }\end{array}$ \\
\hline-1 worse & $0 \%$ & $3 \%$ & \multirow{7}{*}{$p=0.330$} \\
\hline 0 no change & $27.9 \%$ & $15.2 \%$ & \\
\hline 1 moderate improvement & $44.2 \%$ & $42.4 \%$ & \\
\hline 2 good improvement & $16.3 \%$ & $30.3 \%$ & \\
\hline 3 cured & $11.6 \%$ & $9.1 \%$ & \\
\hline mean score & 1.1 & 1.3 & \\
\hline median score (IQR) & $1(0-2)$ & $1(1-2)$ & \\
\hline
\end{tabular}

*Mann Whitney U test

diseases such as Wegener's disease or granulomatous disease (53-54), urinary and respiratory tract infections and for prophylaxis and treatment of Pneumocystis carinii infection ${ }^{(22,55)}$, and it is known to be used in the treatment of CRS in short courses ${ }^{(56,57),}$ we did not find any data in literature on the prolonged usage in patients with recalcitrant CRS.

In the scarce amount of literature on long-term low-dose antibiotic treatment in patients with recalcitrant CRS, most data report on macrolides. Clinical studies support the view that macrolides are likely to be beneficial in most patients who have CRS. Besides their ability to accumulate in inflammatory cells at concentrations up to several 100-folds higher than concentrations in extracellular fluids, macrolides are known to increase mucociliary transport, reduce goblet cell secretion, accelerate apoptosis of neutrophils, reduce expression of cell surface adhesion molecules, alter structure and function of biofilm, and macrolides have shown to decrease levels of IL-5, IL-6, IL-8, GM-CSF, 


\begin{tabular}{|lccc}
\hline \multicolumn{1}{|c}{ symptoms } & $\begin{array}{c}\text { responders } \\
\mathbf{n = 5 9}\end{array}$ & $\begin{array}{c}\text { non-respond- } \\
\text { ers } n=17\end{array}$ & $\begin{array}{c}\text { p-value Fischer } \\
\text { exact test }\end{array}$ \\
\hline allergy & $25(42 \%)$ & $5(29 \%)$ & 0.41 \\
asthma & $32(54 \%)$ & $8(47 \%)$ & 0.78 \\
mild polyposis & $37(63 \%)$ & $12(71 \%)$ & 0.77 \\
ASA triad & $5(9 \%)$ & $3(18 \%)$ & 0.37 \\
smoking & $4(7 \%)$ & $3(18 \%)$ & 0.18 \\
\hline endoscopy & responders & non-respond- & p-value Fischer \\
& $n=64$ & exs n=12 & 0.11 \\
allergy & $28(44 \%)$ & $2(17 \%)$ & 1.00 \\
asthma & $34(53 \%)$ & $6(50 \%)$ & 0.19 \\
mild polyposis & $39(61 \%)$ & $10(83 \%)$ & 0.11 \\
ASA triad & $5(8 \%)$ & $3(25 \%)$ & 0.07 \\
smoking & $4(6 \%)$ & $3(25 \%)$ &
\end{tabular}

TGF- $\beta$, and TNF- $\alpha^{(24,25,57-61)}$. There is also evidence in vitro showing that macrolides reduce the virulence and tissue damage caused by chronic bacterial colonization without necessarily eradicating the bacteria ${ }^{(62)}$. Trimethoprim-sulfamethoxazole has been suggested to influence $T$ cell function and to interfere with the production of specific oxygen-derived radicals ${ }^{(63)}$.

In this presented group of patients, we found that 1) patients responded well to the long-term low-dose antibiotic treatment; 2 ) response decreased slightly over time after cessation of the antibiotic treatment, but results were still satisfactory at the end of the 5 months follow-up; 3 ) there was no difference between the two evaluated antibiotic families. A substantial reduction in sinonasal symptoms of $78 \%$, and an improvement of mucosal conditions of $84 \%$ was found. More detailed statistical analysis comparing both antibiotics families, demonstrated no significant differences between them. It is therefore not possible, based on these data, to elect one antibiotic over the other. In the performed subgroup analysis, we evaluated allergy, blood eosinophils, asthma, mild nasal polyposis, ASA triad and smoking. Although no statistical significant differences were found, it is remarkable to find a higher percentage of allergies in the responding group but not a higher percentage of blood eosinophils. Perhaps this could be a pointer to the immunomodulatory effects of the antibiotics. Another observation was the higher incidence of smoking in de non-responders group. This puts the importance of encouragement of smoking again into the spotlight ${ }^{(64)}$.

Multiple comments can be made on this study. We performed a retrospective evaluation with many shortcomings and pitfalls coming along with it. Before we discuss some of them, we stress the recalcitrant nature of CRS in this studied population, for which all conventional treatment options have proven to be insufficient. Patients suffering from this recalcitrant disease are hard to motivate to participate in a placebo-controlled trial, because they do not want to risk the chance on placebo. For that reason, we felt it was useful to do this retrospective analyses were all patients that received antibiotics could be evaluated. However, the absence of a control-group in this evaluation inhibits the development of strong conclusions. What would be the result of placebo compared with trimethoprim-sulfamethoxazole and macrolides? In the first performed, double-blind, randomized, placebo-controlled trial on the efficacy of 3 months of macrolide treatment in 64 CRS-patients, no significant differences were found. However, a significant benefit of macrolides over placebo was shown in a subpopulation of patients with low $\lg { }^{(29)}$. In the second performed RCT on the efficacy of an equal dose azithromycin in patients with recalcitrant CRS, no significant difference between the azithromycin, and placebo was found either (Videler et al., unpublished observations). However, contrary to both placebo-controlled studies, the present study and the non-placebo-controlled study from Ragab (28), demonstrate a significant positive effect on some patients. In the placebo-controlled studies, both the treatment and the placebo did not have a significant effect on the symptomatology nor the endoscopic results. Especially in our own study, that we know was performed in a group of patients partly overlapping with the presented population of this study, this difference was very clear: very little effect of macrolide in the placebo-controlled study and a significant effect of the macrolide in the non-placebo controlled trial. We hypothesize that the selection of patients that are willing to participate in a randomized placebo controlled trial differs sub- 
Figure 1. Total responders in time for symptoms.

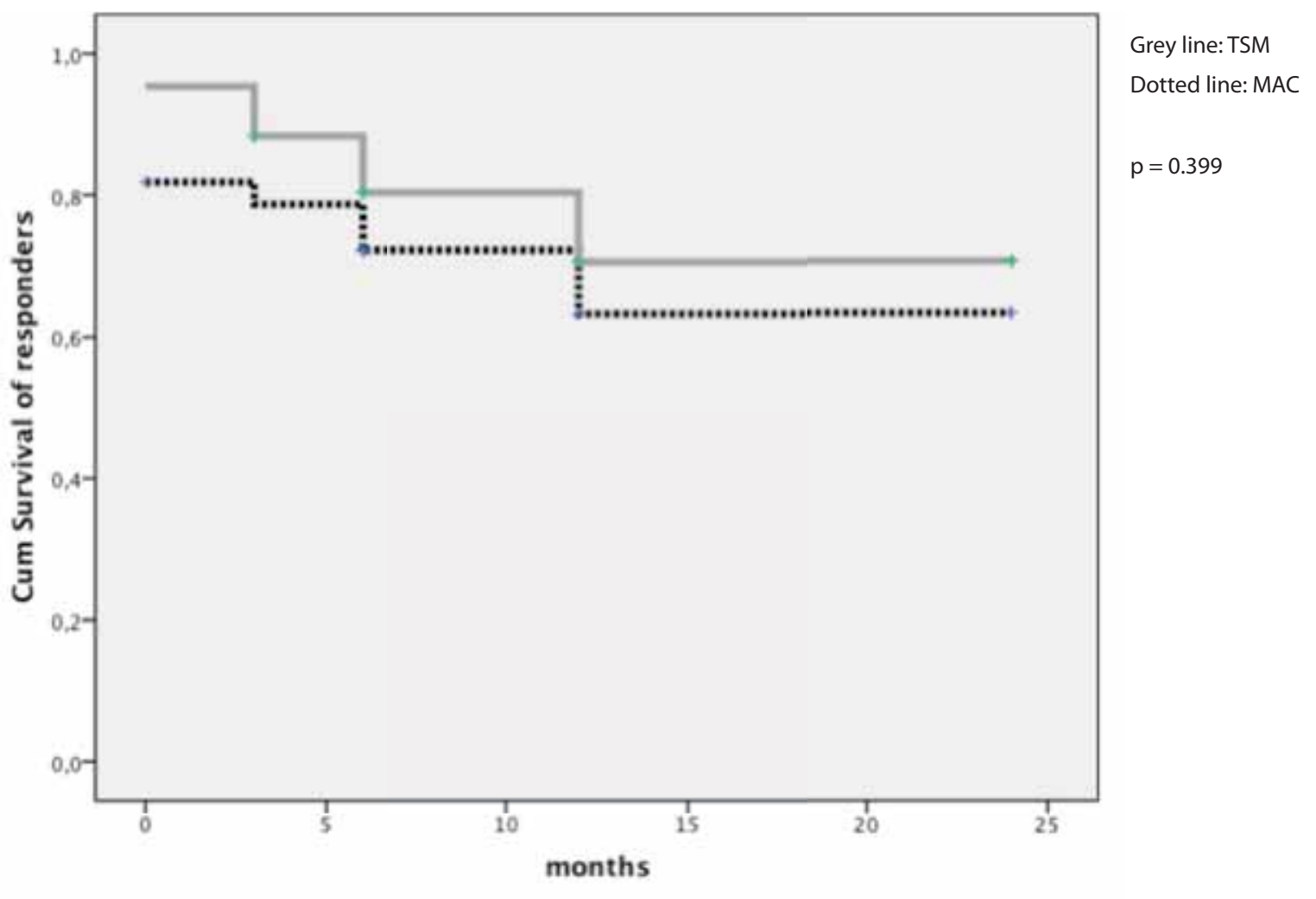

stantially from the population we treat in daily clinical practice. This is a phenomenon that has been discussed in recent years especially in trials dealing with serious chronic disease ${ }^{(65-67)}$. In an attempt to create a homogeneous population, researchers tend to use strict inclusion criteria. This may lead to a selection bias of the enrolled patients, who may substantially differ from the population encountered in clinical practice.

Another comment on this study could be the appropriate dosage of the antibiotics. Some clinicians start a prolonged treatment with the standard dose for treating acute infections and after 2 weeks lower the dose to half. This was done for trimethoprim-sufamethoxazole and clarythromycin. Azithromycin has a longer half-life time, which justifies a dosage once weekly. Before starting a long-term low-dose antibiotics treatment, the patient has to be informed that it takes 4 to 8 weeks for the treatment to have an effect, and that a proper evaluation cannot be performed until the treatment period has covered 10 to 12 weeks. It is suggested that if the treatment is successful it should be prolonged for several months. We normally start with an arbitrary period of at least 3 months.

The follow-up of around 5 months could be another point of criticism. The reader should keep in mind that recalcitrant CRS in this group of patients is hard to combat and most patients continuously demand new steps in treatment process. On the other hand, patients who did well on the prolonged medical therapy were sent back to their secondary care centres.

Patients were seen by a team of rhinologists at the outpatient clinic. Although they work closely together, follow protocols and frequently discuss individual patients, there is always the risk of inter-observer bias. While collecting the data for this retrospective evaluation, patient records were studied at least by two of the authors. Different opinions were thoroughly discussed and in doubt the most negative opinion (e.g. between moderate and good response) prevailed.

In the debate on prolonged administration of antibiotics, the development of resistant bacteria is a returning item. To date, an all including conclusion cannot be made, but it is suggested that the risk of selecting resistant bacteria is low ${ }^{(24)}$. In this present investigation, we did not evaluate bacterial culture results consistently and we consequently cannot present data on resistance development in this whole group. In the recently performed RCT that we have discussed shortly above, we did not find a relevant increase of resistance in the cultured bacteria.

Although long-term low-dose antibiotic treatment seems to be a promising option, as we see in a selection of patient at the outpatient clinic, it is too early to formulate firm conclusions. An important target for this future work could be the identification 
Figure 2. Total responders in time for endoscopic findings.

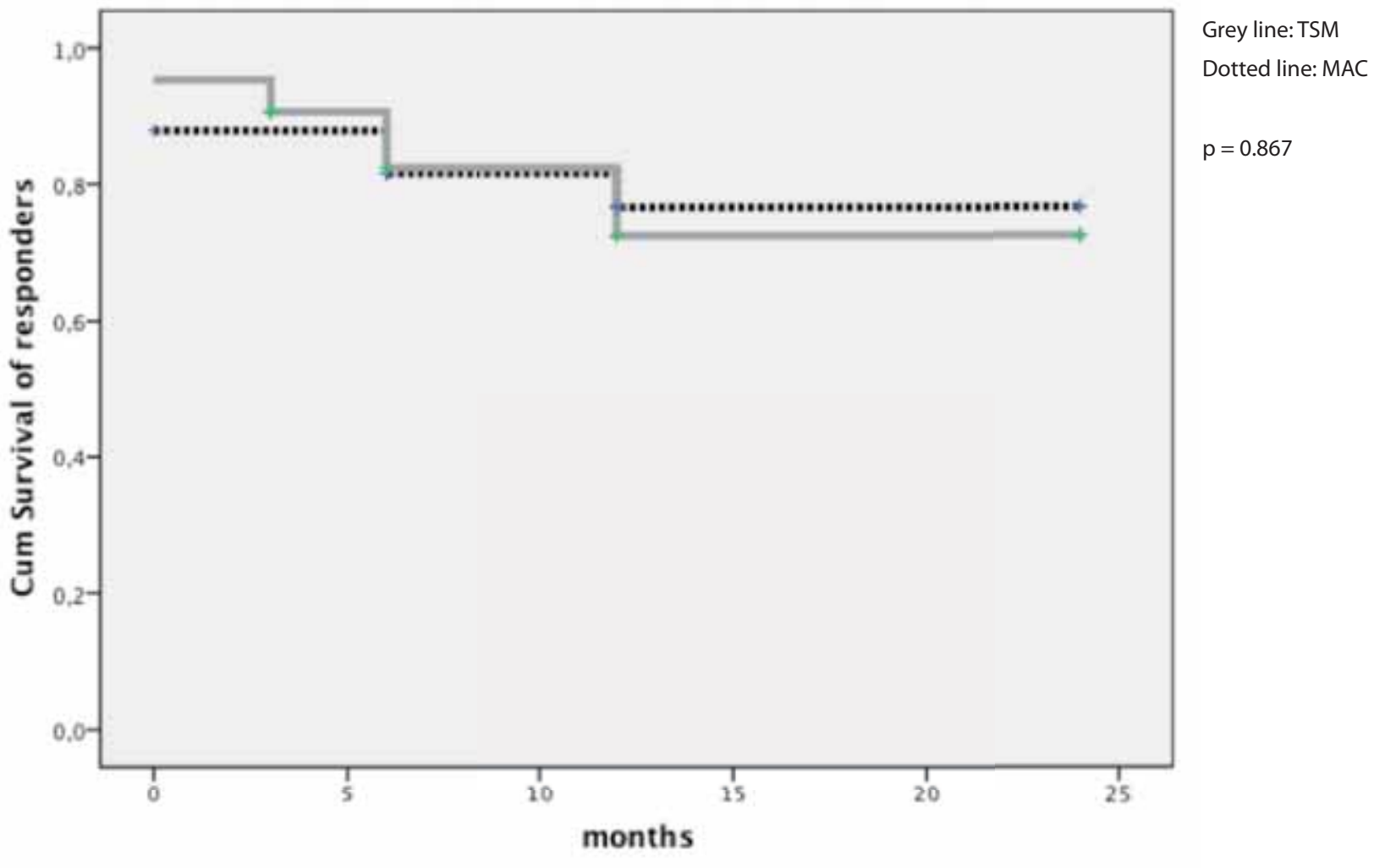

of the group of responders and or poor prognostic factors in CRS patients. Suzuki et al., reported on elevated IgE levels and substantial eosinophilia in smear, tissue or blood as being poor prognostic factors ${ }^{(68)}$. We could not find relevant subgroups in this study but IgE levels were only measured in a subgroup of the patients (data not shown). In some studies, the presence of nasal polyps also has been reported as being unfavourable for the efficacy of long-term low-dose antibiotic treatment ${ }^{(24)}$. Further identification of subgroups is necessary. In our opinion, long-term low-dose treatment could be a promising alternative treatment option in the battle against recalcitrant CRS in a selected group of patients. Especially when the patient is not motivated for additional surgery, significant co-morbidity increases the operation risks. It can also help patients who suffer from CRS complaints during a particular season of the year, and create optimal conditions for paranasal recovery in the postoperative period. However, it is still difficult to tell which patient would benefit from this treatment and more research in this field is urgently required.

\section{Author contribution}

SMR, CG, FWvdM, and WJF are members of the AMC rhinology team and treated the patients. WJMV and WJF designed the study, and together with $\mathrm{KvH}$ collected the data, and were involved in literature search. Data interpretation and writing were performed by WJMV and WJF.

\section{Conflict of interest}

None

\section{Acknowledgments}

The authors thank N. van Geloven for her assistance in the statistical analysis.

\section{References}

1 Levine $\mathrm{HL}$. Functional endoscopic sinus surgery: evaluation, surgery, and follow-up of 250 patients. Laryngoscope. 1990; 100: 79-84.

2 Vleming M, Middelweerd MJ, de Vries N.
Good results of endoscopic paranasal sinus surgery for chronic or recurrent sinusitis and for nasal polyps. Ned Tijdschr Geneeskd. 1993; 137: 1453-1456.

3 Matthews BL, Smith LE, Jones R, Miller C, Brookschmidt JK. Endoscopic sinus surgery: outcome in 155 cases. Otolaryngol Head Neck Surg. 1991; 104: 244-246.

4 Gliklich RE, Metson R. Effect of sinus surgery on quality of life. Otolaryngol Head Neck Surg. 1997; 117: 12-17.

5 Harkness P, Brown P, Fowler S, Topham J. A 
national audit of sinus surgery. Results of the Royal College of Surgeons of England comparative audit of ENT surgery. Clin Otolaryngol Allied Sci. 1997; 22: 147-151.

6 Senior BA, Kennedy DW, Tanabodee J, Kroger $H$, Hassab M, Lanza D. Long-term results of functional endoscopic sinus surgery. Laryngoscope. 1998; 108: 151-157.

7 Chiu AG, Palmer JN, Woodworth BA, et al. Baby shampoo nasal irrigations for the symptomatic post-functional endoscopic sinus surgery patient. Am J Rhinol. 2008; 22: 34-37.

8 Hansen FS, Djupesland PG, Fokkens WJ. Preliminary efficacy of fluticasone delivered by a novel device in recalcitrant chronic rhinosinusitis. Rhinology. 2010; 48: 292-299.

9 Ragab SM, Lund VJ, Scadding G, Saleh HA, Khalifa MA. Impact of chronic rhinosinusitis therapy on quality of life: a prospective randomized controlled trial. Rhinology. 2010; 48: 305-311.

10 Proimos E, Papadakis CE, Chimona TS, Kiagiadaki D, Ferekidis E, Yiotakis J. The effect of functional endoscopic sinus surgery on patients with asthma and CRS with nasal polyps. Rhinology. 2010; 48: 331-338.

11 Videler WJ, van Drunen CM, van der Meulen FW, Fokkens WJ. Radical surgery: effect on quality of life and pain in chronic rhinosinusitis. Otolaryngol Head Neck Surg. 2007; 136: 261-267.

12 Videler WJ, Wreesmann VB, van der Meulen FW, Knegt PP, Fokkens WJ. Repetitive endoscopic sinus surgery failure: a role for radical surgery? Otolaryngol Head Neck Surg. 2006; 134: 586-591

13 Wreesmann VB, Fokkens WJ, Knegt PP. Refractory chronic sinusitis: evaluation of symptom improvement after Denker's procedure. Otolaryngol Head Neck Surg. 2001; 125: 495-500

14 Weber R, Draf W, Kratzsch B, Hosemann W, Schaefer SD. Modern concepts of frontal sinus surgery. Laryngoscope. 2001; 111: 137146.

15 Weber R, Draf W, Keerl R, Behm K, Schick B. Long-term results of endonasal frontal sinus surgery. HNO. 1996; 44: 503-509.

16 Draf W, Weber R, Keerl R, Constantinidis J. Current aspects of frontal sinus surgery. I: Endonasal frontal sinus drainage in inflammatory diseases of the paranasal sinuses. HNO. 1995; 43: 352-357.

17 Proctor RA. Role of folate antagonists in the treatment of methicillin-resistant Staphylococcus aureus infection. Clin Infect Dis. 2008; 46: 584-593

18 Zander J, Besier S, Ackermann H, Wichelhaus TA. Synergistic antimicrobial activities of folic acid antagonists and nucleoside analogs. Antimicrob Agents Chemother 2010; 54: 1226-1231

19 Omura S. Macrolide antibiotics: chemistry, biology and practice. Amsterdam; Boston: Academic Press:

20 Tamaoki J. The effects of macrolides on inflammatory cells. Chest. 2004; 125: 41S50S; quiz 51S

21 Masters PA, O'Bryan TA, Zurlo J, Miller DQ, Joshi N. Trimethoprim-sulfamethoxazole revisited. Arch Intern Med. 2003; 163: 402410

22 Cunha BA. New uses for older antibiotics. The 'rediscovery' of four beneficial and costeffective antimicrobials. Postgrad Med. 1997; 101: 68-70, 73-4, 79-80.

23 J Mermin, JR Lule, JP Ekwaru, C Pitter, Should cotrimoxazole prophylaxis be taken by all adults with HIV in Africa? AIDS. 2005;19: 845846

24 Cervin A, Kalm O, Sandkull P, Lindberg S. Oneyear low-dose erythromycin treatment of persistent chronic sinusitis after sinus surgery: clinical outcome and effects on mucociliary parameters and nasal nitric oxide. Otolaryngol Head Neck Surg. 2002; 126: 481-489.

25 Suzuki H, Shimomura A, Ikeda K, Oshima T, Takasaka T. Effects of long-term low-dose macrolide administration on neutrophil recruitment and IL-8 in the nasal discharge of chronic sinusitis patients. Tohoku J Exp Med. 1997; 182: 115-124.

26 Ichimura K, Shimazaki Y, Ishibashi T, Higo R. Effect of new macrolide roxithromycin upon nasal polyps associated with chronic sinusitis. Auris Nasus Larynx. 1996; 23: 48-56.

27 Hashiba M, Baba S. Efficacy of long-term administration of clarithromycin in the treatment of intractable chronic sinusitis. Acta Otolaryngol Suppl. 1996; 525: 73-78.

28 Ragab SM, Lund VJ, Scadding G. Evaluation of the medical and surgical treatment of chronic rhinosinusitis: a prospective, randomised, controlled trial. Laryngoscope. 2004; 114: 923-930.

29 Wallwork B, Coman W, Mackay-Sim A, Greiff L, Cervin A. A double-blind, randomized, placebo-controlled trial of macrolide in the treatment of chronic rhinosinusitis. Laryngoscope. 2006; 116: 189-193.

30 van Zele T, Gevaert P, Holtappels G, Beule A, Wormald PJ, et al. Oral steroids and doxycycline: Two different approaches to treat nasal polyps. J Allergy Clin Immunol. 2010; 125: 1069-1076.

31 Fokkens W, Lund V, Mullol J, European Position Paper on Rhinosinusitis and Nasal Polyps group. European position paper on rhinosinusitis and nasal polyps 2007. Rhinol Suppl. 2007: 1-136.

32 Marchisio P, Principi N, Sala E, Lanzoni L, Sorella S, Massimini A. Comparative study of once-weekly azithromycin and oncedaily amoxicillin treatments in prevention of recurrent acute otitis media in children. Antimicrob Agents Chemother. 1996; 40: 2732-2736

33 Foulds G, Shepard RM, Johnson RB. The pharmacokinetics of azithromycin in human serum and tissues. J Antimicrob Chemother. 1990; 25 Suppl A: 73-82.

34 Nahata MC, Koranyi KI, Luke DR, Foulds G. Pharmacokinetics of azithromycin in pediatric patients with acute otitis media. Antimicrob Agents Chemother. 1995; 39: 1875-1877.

35 Pukander J, Rautianen M. Penetration of azithromycin into middle ear effusions in acute and secretory otitis media in children. J Antimicrob Chemother. 1996; 37 Suppl C:
53-61.

36 Rott O, Mignon-Godefroy K, Fleischer B Charreire J, Cash E. Superantigens induce primary $T$ cell responses to soluble autoantigens by a non- $V$ beta-specific mechanism of bystander activation. Cell Immunol. 1995; 161: 158-165.

37 Gevaert P, Holtappels G, Johansson SG, Cuvelier C, Cauwenberge P, Bachert C. Organization of secondary lymphoid tissue and local lgE formation to Staphylococcus aureus enterotoxins in nasal polyp tissue. Allergy. 2005; 60: 71-79.

38 Bachert C, Gevaert P, Holtappels G, Johansson SG, van Cauwenberge P. Total and specific lgE in nasal polyps is related to local eosinophilic inflammation. J Allergy Clin Immunol. 2001; 107: 607-614.

39 Zhang N, Gevaert P, van Zele T, et al. An update on the impact of Staphylococcus aureus enterotoxins in chronic sinusitis with nasal polyposis. Rhinology. 2005; 43: 162168.

40 Seiberling KA, Grammer L, Kern RC. Chronic rhinosinusitis and superantigens. Otolaryngol Clin North Am. 2005; 38: 12151236.

41 Davis LJ, Kita H. Pathogenesis of chronic rhinosinusitis: role of airborne fungi and bacteria. Immunol Allergy Clin North Am. 2004; 24: 59-73.

42 Braun H, Buzina W, Freudenschuss K, Beham A, Stammberger $H$. 'Eosinophilic fungal rhinosinusitis': a common disorder in Europe? Laryngoscope. 2003; 113: 264-269.

43 Shin SH, Ponikau JU, Sherris DA, et al. Chronic rhinosinusitis: an enhanced immune response to ubiquitous airborne fungi. J Allergy Clin Immunol. 2004; 114: 1369-1375.

44 Ponikau JU, Sherris DA, Kern EB, et al. The diagnosis and incidence of allergic fungal sinusitis. Mayo Clin Proc. 1999; 74: 877-884.

45 Ponikau JU, Sherris DA, Weaver A, Kita H. Treatment of chronic rhinosinusitis with intranasal amphotericin B: a randomized, placebo-controlled, double-blind pilot trial. J Allergy Clin Immunol. 2005; 115: 125-131.

46 Khalid AN, Hunt J, Perloff JR, Kennedy DW. The role of bone in chronic rhinosinusitis. Laryngoscope. 2002; 112: 1951-1957.

47 Lee JT, Kennedy DW, Palmer JN, Feldman M, Chiu AG. The incidence of concurrent osteitis in patients with chronic rhinosinusitis: a clinicopathological study. Am J Rhinol. 2006; 20: 278-282.

48 Kennedy DW, Senior BA, Gannon FH, Montone KT, Hwang P, Lanza DC. Histology and histomorphometry of ethmoid bone in chronic rhinosinusitis. Laryngoscope. 1998; 108: 502-507.

49 Perloff JR, Gannon FH, Bolger WE, Montone KT, Orlandi R, Kennedy DW. Bone involvement in sinusitis: an apparent pathway for the spread of disease. Laryngoscope. 2000; 110: 2095-2099.

50 Post JC, Stoodley P, Hall-Stoodley L, Ehrlich $\mathrm{GD}$. The role of biofilms in otolaryngologic infections. Curr Opin Otolaryngol Head Neck Surg. 2004; 12: 185-190.

51 Clement $S$, Vaudaux $P$, Francois $P$, et al. 
Evidence of an intracellular reservoir in the nasal mucosa of patients with recurrent Staphylococcus aureus rhinosinusitis. Infect Dis. 2005; 192: 1023-1028.

52 Plouin-Gaudon I, Clement S, Huggler E, et al. Intracellular residency is frequently associated with recurrent Staphylococcus aureus rhinosinusitis. Rhinology. 2006; 44: 249-254.

53 Stegeman CA, Tervaert JW, de Jong PE, Kallenberg CG. Trimethoprimsulfamethoxazole (co-trimoxazole) for the prevention of relapses of Wegener's granulomatosis. Dutch Co-Trimoxazole Wegener Study Group. N Engl J Med. 1996; 335: 16-20.

54 Liese J, Kloos S, Jendrossek V, et al. Longterm follow-up and outcome of 39 patients with chronic granulomatous disease. Pediatr. 2000; 137: 687-693.

55 Hughes WT, Dankner WM, Yogev R, et al. Comparison of atovaquone and azithromycin with trimethoprim-sulfamethoxazole for the prevention of serious bacterial infections in children with HIV infection. Clin Infect Dis. 2005: 40: 136-145.

56 Aukema AA, Fokkens WJ. Chronic rhinosinusitis: management for optimal outcomes. Treat Respir Med. 2004; 3: 97-105.

57 Nonaka M, Pawankar R, Saji F, Yagi T. Effect of roxithromycin on IL-8 synthesis and proliferation of nasal polyp fibroblasts. Acta Otolaryngol Suppl. 1998; 539: 71-75.

58 Kohyama T, Takizawa H, Kawasaki S, Akiyama $N$, Sato M, Ito K. Fourteen-member macrolides inhibit interleukin-8 release by human eosinophils from atopic donors. Antimicrob Agents Chemother. 1999; 43: 907-911.

59 Miyanohara T, Ushikai M, Matsune S, Ueno K, Katahira S, Kurono Y. Effects of clarithromycin on cultured human nasal epithelial cells and fibroblasts. Laryngoscope. 2000; 110 : 126-131.

60 Cervin A. The anti-inflammatory effect of erythromycin and its derivatives, with special reference to nasal polyposis and chronic sinusitis. Acta Otolaryngol. 2001; 121: 83-92.

61 Scadding GK, Lund VJ, Darby YC. The effect of long-term antibiotic therapy upon ciliary beat frequency in chronic rhinosinusitis. J Laryngol Otol. 1995; 109: 24-26.

62 Sofer D, Gilboa-Garber N, Belz A, Garber NC. 'Subinhibitory' erythromycin represses production of Pseudomonas aeruginosa lectins, autoinducer and virulence factors. Chemotherapy. 1999; 45: 335-341.

63 Rozin A, Schapira D, Braun-Moscovici Y, Nahir AM. Cotrimoxazole treatment for rheumatoid arthritis. Semin Arthritis Rheum. 2001; 31: 133-141.

64 Briggs RD, Wright ST, Cordes S, Calhoun KH. Smoking in chronic rhinosinusitis: a predictor of poor long-term outcome after endoscopic sinus surgery. Laryngoscope. 2004; 114: 126-128.

65 Storms W. Clinical trials: are these your patients? J Allergy Clin Immunol. 2003; 112; S107-S111.

66 Falagas ME, Vouloumanou EK, Sgouros K, Athanasiou S, Peppas G, Siempos II. Patients included in randomised controlled trials do not represent those seen in clinical practice: focus on antimicrobial agents. Int J Antimicrob Agents. 2010; 36: 1-13.

67 Kalata P, Martus P, Zettl H, et al. Differences between clinical trial participants and patients in a population-based registry: the German Rectal Cancer Study vs. the Rostock Cancer Registry. Dis Colon Rectum. 2009; 52: 425-437.

68 Suzuki H, Ikeda K, Honma R, et al. Prognostic factors of chronic rhinosinusitis under longterm low-dose macrolide therapy. ORL J Otorhinolaryngol Relat Spec. 2000; 62: 121 127.

W.J. Fokkens, MD, PhD

Department of Otorhinolaryngology

Academic Medical Centre (AMC)

Meibergdreef 9

1105 AZ Amsterdam

the Netherlands

Tel: +31-20-566 3789

Fax: +31-20-691 3850

E-mail:W.J.Fokkens@amc.uva.nl 